\title{
Columba livia time budget in the conditions of Kazan in spring
}

\author{
Aizat Basyyrov, Tamila Leonova \\ Kazan Federal University, 420008, Kazan, Russia
}

\begin{abstract}
The daily time budgets of the rock pigeon (Columba livia) in the spring were studied basing on the example of birds with different foraging strategies. The connection between daylight hours and the birds' night sleep was revealed. The relation between the daily routine and various forms of activity in birds with different foraging strategies was revealed.
\end{abstract}

\section{Introduction}

The ecology of Columba livia is of interest due to the large number of this species in urban areas. Synanthropization is associated with a multifaceted and deep adaptation of the birds' biology, but new behavioural, ecological or morphofunctional adaptations may appear as well. The fact that many bird species inhabit urban areas testifies to the environment suitability for their habitation and activity. To assess the quality of the urban landscape as a habitat, it is essential to study the time budgets of the birds. The ratio of time spent on various forms of activity indicates how favourable the environment is for the existence of the species, as well as the degree of the niche it occupies. In addition, the understanding of the time-use and foraging strategies can reveal the peculiarities of the adaptive behaviour of the rock pigeon in the urban environment in detail. Due to the fact that the time budgets of many bird species are insufficiently studied, the problem remains unresolved and requires further research. The study of the birds' time budget remains one of the urgent problems of ecology.

\section{Materials and methods}

The research was carried out on the territory of Kazan. This is one of the largest economic, political, scientific, cultural and sports centres in the Russian Federation. The city is located in the east of the European part of Russia. The city covers an area of 425 square kilometres and includes 7 administrative regions. There are rolling plains, the climate is moderately continental.

We opted for the direct timing method to obtain data on the time budget of birds in urban environment. The bird under analysis must constantly be in the field of vision, differ from other individuals by unique characteristics or marking. A stopwatch is used to note the time interval during which the bird demonstrates a certain type of activity. Due to the fact that it is very difficult to conduct continuous observations for 24 hours non-stop, the daily 
record is collected in parts. It is even allowed to observe different individuals, at different times and on different days, but always in identical conditions [1].

In rock pigeons, several forms of activity are distinguished, which determine their behaviour during the day. According to E.V. Potapova [2], we identified the following forms of activity: awakening, feeding, drinking, walking, flying, cleaning feathers, daytime rest, mating behaviour, preparing for going to sleep and night's sleep.

When defining pigeons according to the foraging strategy, we used the classification proposed by L.K. Vanicheva [3]: "flyers", "collectors" and "scavengers". "Flyers" are individuals that daily cover several kilometers from their night shelters to the forage site; "Collectors" are individuals that find food on pavements and roadsides, transport stops, in public gardens and recreation parks; "Scavengers" are individuals feeding on kitchen waste in dustbin in the courtyards of residential buildings. Our research was based on the time study of "collectors" and "scavengers" in spring.

The observations were conducted at three model sites in different biotopes. At observation point No.1, five-storey buildings prevail, car traffic is insignificant, and local residents occasionally feed birds. At this point, pigeons are attracted by open dustbins and the presence of a warm cover slab of a sewer well. On the territory of observation point No.2, Columba livia are attracted by the presence of open dustbins and daily feeding. The site is characterized by a lot of passers-by and heavy traffic. Observation point No.3 includes a city square and a bus stop.

\section{Results and discussion}

The time budget of birds is highly dependent on a combination of various factors. First of all, it is necessary to highlight the season and prevailing climatic indicators of temperature, humidity, precipitation, etc. corresponding to the season. Secondly, the lifecycle phase of the bird should be distinguished; for example, during the mating season, nesting, incubating eggs and other phases, birds demonstrate certain behaviour and the corresponding distribution of the time budget by the form of activity. Weather conditions prevailing at a particular moment of time are equally crucial, since rain, snow, strong winds and frost correct the nature of bird activity [2].

The morning activity of rock pigeons began with their arrival at the forage site, and it is important to note that the activity of the pigeons begins before sunrise, in our case, 12 minutes before it. From the first minutes of activity, the birds started looking for food or began feeding. Pigeons perched on dustbins and examined them, or flocked to the cover slab of a sewer well, where people had put food. It took the birds at this study site 1.96 hours to feed, which is $8.20 \%$ of the daily time budget, and 1.68 hours $(7 \%)$ for foraging. After feeding, some individuals returned to the roof of the building, where their shelter was located. There they perched on metal fences and rested: some of the birds were perching, some were watching the area or watching the passers-by. The other part of the birds stayed on the cover slab, on which the pigeons were lying or perching, raising the feathers, and keeping themselves warm due to the heat from the sewer. In this research, this type of activity was considered as a daytime rest, for which the birds allocated $27.5 \%$ of the daily time budget, which is 6.59 hours.

During the day, we observed periodic circular flights of the colony of rock pigeons. They were noted approximately every 20-30 minutes, comprised a maximum of 4 laps and lasted 10-15 seconds per 1 lap. Such flights were usually performed by pigeons perching on the roof of the building and on the power lines. Supposedly, such flights were made to inspect the territory or search for a warm place, or in this way the birds simply "stretched their wings" and the total cost of such flights, fluttering and short-term flights accounted for 0.31 hour per day $(1.3 \%)$. 
During daytime activity, pigeons preened their feathers, but such actions were rarely observed. This activity took 0.26 hour, or $1.1 \%$ of the daily time budget. In the cold season, birds preen their feathers in order to increase the air space and keep warm. In spring, preening is attributable to the molting process. In our study, the amount of time spent on this type of activity is very small. March is the first month of spring, and birds already begin to molt, but the process is quite moderate, not intense. At this period there is still snow and it is rather cold outside. During the study period, the temperature in March varied from $-7{ }^{\circ} \mathrm{C}$ to $+1{ }^{\circ} \mathrm{C}$. However, at the same time, the covers of the sewer wells located at observation site No.1 acted as a source of heat, due to which the pigeons kept warm when it was cold. Consequently, birds lost the necessity to preen their feathers in order to keep warm. Taking into account the above two reasons, such a small amount of time spent on preening in March is quite justified.

In March, at site No.1, mating calls of males were observed extremely rarely and there were few registrations of the mating dance during male courtship displays to a female, accompanied by cooing. In total, the costs for this type of activity amounted to $0.37 \%$ of the daily time budget, that is, 0.09 hour.

We established that the pigeon activity finished at observation site No.1 at 17:25 in March. The birds flew into the attic on the roof of the five-storey building 41 minutes before sunset. This phenomenon proves that the pigeons try to return to their night shelter before dark.

In accordance with the data obtained on the beginning and end of the rock pigeon activity, we calculated the time it spent on night sleep. In the course of the study, it was impossible to observe and calculate such activities as awakening and preparation for sleep. Therefore, the time the birds spent on these forms of activity is included in the time spent on night sleep. In other words, night sleep implies sleep itself, the time spent on preparation for sleep, and the time of awakening. Thus, the rest time, or night sleep, in pigeons accounted for almost half (51\%) of the daily time budget, that is, 12.25 hours.

It is known that the attics of buildings are the key living space of the ecological niche of the pigeon. There the birds mate, reproduce and defecate, organize their nests, resting sites, roosting sites and night shelters, form trophic and topical connections, develop social behaviour (homing, imprinting). According to other researchers, life in attics in urban environment takes up a large share of the pigeon's time budget: in summer it takes $25-40 \%$ of time per 24 hours, in winter it amounts to $65-70 \%$ of the same period of time [4].

In April, the birds spent $10.96 \%$ of their daily time budget on feeding at the site No.2, $9.17 \%$ - on foraging, which is 2.63 and 2.20 hours respectively. It should be clarified that "foraging" is an intermediate activity of the pigeon between feeding and walking. This was the term used in the work, since most often it was impossible to distinguish between these two forms of behaviour. Feeding is different from foraging in that during the former the bird stops completely in order to consume the food, which cannot be said about the latter, during which the pigeon mostly walks and searches for food, making single pecks every few steps. In other words, "foraging" is walking associated with feeding. However, birds spent $4.39 \%$ of the daily time budget, or 1.05 hours, on pure walking.

In April, the number of cases related to the mating behaviour of pigeons increased. Exhibition of certain postures and male mating dancing accompanied by cooing was quite often noticed. In total, the costs of this form of activity amounted to $1.3 \%$ of the daily time budget.

At observation site No.3, Columba livia belonged to the group of "collectors". The pigeons first appeared in the park in early April, when the snow had melted and people began to visit the park. As the first visitors came into the park, the birds appeared as well.

It should be noted that the pigeons are not limited to the territory of the park, they periodically visit the nearest bus stop, flying away from it or walking towards it. On the 
way to the stop, birds also walk and seek food. Foraging takes the rock pigeon $17.16 \%$ of the daily time budget.

Concerning the behaviour of pigeons at observation site No.3, several features were noted. Although the birds are fed by people, they still do not let people close. The flight zone reaches 1.5-2 meters, when the birds are fed, they do not hurry to start eating the food, but carefully and cautiously approach it and quickly fly off or run away as soon as a person makes a sudden movement. Since observation point No.3 is not characterized by the abundance of food resources, fights between pigeons can frequently be noted and intraspecific competition is rather pronounced. Such hostile behaviour in pigeons takes 0.12 hour a day, or $0.5 \%$ of the daily time budget.

The pigeons spend $10.58 \%$ of their day walking, which is a very expected behaviour for birds with a similar foraging strategy. It should be taken into account that these birds spend most of the daylight hours, namely 4.12 hours at the time of our study, on foraging. Thus, such a significant amount of time spent on these forms of activity explains the lack of time for daytime rest. Since the "collectors" devote more than half of their time budget to foraging, they have only 2.38 hours a day for rest. While walking, birds can stop, look around or stand still, remaining in this condition from 30 seconds to several minutes. Supposedly, such actions also refer to a kind of short-term rest while walking or foraging.

\section{Conclusion}

Rock pigeon time budgets directly depend on the season and the duration of daylight hours. The study showed that when daylight hours increase, the time spent on night sleep decreases. Thus, every month in spring, the pigeons demonstrated the decreased amount of time spent on night sleep: in March this type of activity took $51 \%$ of the daily time budget, in April - 42.4\%, in May - 35.83\%.

The time of the beginning and end of the birds' daily activity varies regarding the time of sunrise and sunset. Pigeons arrive at the forage site at sunrise (10-20 minutes before sunrise), and fly away to the night shelter before sunset (30-40 minutes before sunset).

The daily routine of the rock pigeon and the time it allocates for certain forms of activity depends on the foraging strategy. The birds of the "collector" type spend most of the day in search of food, allotting $17.16 \%$ of daylight hours to such activities. At the same time, they spend $10.58 \%$ of the daily time budget on walking. Accordingly, the "collector" pigeons devote only $9.92 \%$, or 2.38 hours, to the daytime rest. By comparison, "scavenger" pigeons allow themselves to rest during the day $26-27.5 \%$ of the daylight time (6.24-6.59 hours), due to the abundance and availability of food resources and the absence of necessity to walk and seek food.

It was previously reported that synanthropic pigeons have unusual daily time budget with a longer rest period in comparison to wild pigeons [5]. It has also been claimed that, unlike "flyers" and "collectors", pigeons-"scavengers" do not spend their energy flying and searching for food, and thus their time budget mainly consists of waiting for food waste at dustbins [6]. In view of the above, it is possible to build the series in which the duration of the rest period increases in the following direction: wild pigeons - "flyers" - "collectors" "scavengers".

\section{References}

1. V.R. Dolnik, Trudy ZIN AN SSSR. 113, 3-37 (1982)

2. E.V. Potapova, Izv. Irkutsk. Gos. Univer. Series: Biol.Ecol., 3, №3, 45-51 (2010) 
3. L.K. Vanicheva Synanthropic populations of rock pigeons and their use in monitoring heavy metals in industrial centers of Western Siberia (Novosibirsk, 1997) (in Russian)

4. A.V. Gorbunov, N.S. Nefedova, M.A. Shmidt, Probl. of Particul. Danger. Inf., 2(112), 94-95 (2012)

5. A.S. Ksents, G.H. Ksents, B.A. Laletin, Ornitologicheskie problemy Sibiri, 19-20 (BGU, Barnaul, 1991)

6. A.V. Arinina, I.I. Rakhimov, Adaptive features of the rock pigeon (Columba livia) in an urban environment (on the example of Kazan) (Novoe znanie, Kazan, 2008) 